\title{
Administração fiscal nas províncias do centro: As fronteiras fiscais na América portuguesa (1780-1815)
}

\author{
Tax administration in the central provinces: \\ Tax borders in Portuguese America (1780-1815)
}

\author{
Cláudia Chaves \\ Profesora Universidade Federal de Ouro Preto - UFOP \\ http://orcid.org/0000-0002-0931-0086 \\ claudiachaves@uol.com.br
}

Fecha de recepción: 10 de marzo de 2015

Fecha de aprobación: 29 de mayo de 2015

Sugerencia de citación: Chaves, C. (2015). Administração fiscal nas províncias do centro:

As fronteiras fiscais na América portuguesa (1780-1815). tiempo\&economía, 2(1), 53-68.

\section{Resumo}

Este artigo trata dos conflitos de fronteira entre as províncias de Minas Gerais e São Paulo (1780-1815). Mais especificamente, são abordados os conflitos de jurisdição administrativos a partir da criação das Juntas da Real Fazenda na América portuguesa e da criação do Erário Régio no Império português.

Palavras-chave: Ecomomic História, instituições e mercados financeiros, América Latina Códigos JEL: N2. N26 


\section{Abstract}

This article discusses the border disputes between the provinces of Minas Gerais and São Paulo (1780-1815). More specifically, it examines the conflicts of jurisdiction and financial administration from the creation of the "Juntas da Real Fazenda" in Portuguese America and the creation of the "Erário Régio" in the Portuguese Empire.

Key words: Ecomomic History, Financial Markets and Institutions, Latin America

JEL Codes: N2, N26

Compreender o sistema fiscal do Império português e mais precisamente da América portuguesa a partir da segunda metade do século XVIII, não é tarefa simples. Nesse artigo apresentaremos algumas perspectivas introdutórias que dizem respeito ao sistema de arrecadação, distribuição e de certa forma justiça fazendária representada pelas Juntas da Real Fazenda. O reconhecido processo de centralização administrativa e a reforma nos sistemas econômicos e fiscais a partir das reformas iluministas revelam, sem dúvida, dinâmicas que se desdobraram de forma diferenciada nos dois lados do Atlântico, mas que tiveram com a criação do Erário Régio (1761), e sua independência do Conselho da Fazenda, o seu ponto de partida. ${ }^{1}$ Nos domínios do Império foram atribuídas às Juntas de Fazenda a tarefa de adaptar os novos mecanismos de arrecadação e de administração econômica dos territórios, assim como assumir de forma conjunta a administração econômica com a justiça fazendária. Cândido Batista de Oliveira em seu Sistema Financial do Brasil, ${ }^{2}$ publicado em 1842, nos oferece uma interessante abordagem sobre esse tema. $O$ autor dizia que exercer as atividades contábeis e fiscalizadoras sobre os rendimentos da renda pública, de acordo com as leis vigentes no final do século XVIII, requeria racionalidade e simplicidade no sistema contábil. Entretanto, tais princípios haviam se perdido em sua aplicação no Brasil devido a um emaranhado de vícios e erros. Sua crítica não era original e endossava o testemunho de muitos contemporâneos das próprias Juntas que viam nelas excessivos e perigosos poderes. O ponto fundamental da narrativa de Oliveira, dizia respeito à lógica jurisdicional das Juntas como fator, que desde as instituições basilares, teriam marcado seu fraco desempenho. Ele dizia que o Erário havia sido incumbido da administração fiscal e que ao Conselho da Fazenda cabia o contencioso referente ao fisco e superintendência das rendas públicas que envolviam contratos, uma vez que sobre os demais rendimentos do Estado não havia clareza quanto a sua gestão. No caso das Juntas, elas acumulavam essas duas funções. Para Oliveira, as Juntas possuíam "um corpo composto de disparatados membros, e governado por

1 Veremos mais adiante que a criação das Juntas da Real Fazenda, embora não estivessem diretamente relacionadas com a criação e reforma dos órgãos fazendários em Lisboa foram também, no ultramar relacionadas às chamadas "reformas pombalinas". Atribuídas à ação centralizadora do então ministro de d. José I, Sebastião José de Carvalho e Melo, futuro Marquês de Pombal, tais ações foram reconhecidas em seu conjunto como medidas políticas e econômicas para modernização e racionalização administrativa e, segundo alguns autores, na adoção de um modelo muito semelhante ao cameralismo alemão. Contudo, não concordamos que tais reformas tenham chegado na América ou outras áreas ultramarinas da mesma forma. Nossa hipótese é justamente que e Junta da Real Fazenda representa uma arranjo possível para isso, isto é, as reformas que foram introduzidas para que ela se tornasse um tribunal.

2 Ministro Plenipotenciário enviado à Rússia pelo Imperador d. Pedro I. Publicado em 1842 pela Typographia Privilegiada de Fischer. St. Petersburg. 
duas cabeças eivadas, e discordes". ${ }^{\text {Tal }}$ sistema resultava em distribuição de ofícios vitalícios nas alfândegas, favoritismos, apadrinhamentos, irregularidade nas contas, ausência de transparência nos contratos e, finalmente, prejuízos ao erário.

\section{A administração fiscal na América portuguesa: perspectivas historiográficas}

Grande parte dos estudos que direta ou indiretamente analisaram as Juntas da Fazenda e o Erário Régio concordariam que esses órgãos facilitaram a concentração de poderes locais, que reuniram os membros das elites econômicas em torno de projetos comuns, e, muitas vezes, esses projetos ocorreriam em prejuízo da Real Fazenda. A ênfase seria dada não apenas na relativa autonomia dessas elites em relação à metrópole, mas no maior poder econômico alcançado pelos colonos e pelo poder de administrarem, eles próprios, o sistema de arrecadação e fiscalização fazendária. Um ponto sempre muito lembrado é o fato das arrematações de contratos terem saído da jurisdição do Conselho Ultramarino e ter passado diretamente para as Juntas. Estas precisavam prestar contas, administração fiscal, ao Erário Régio. Uma questão quase nunca mencionada é o fato das Juntas serem muito mais que simples repartições fiscais e que o seu maior poder derivava de possuírem o status de tribunal. A criação da Junta da Real Fazenda da Bahia em 1765 suscitará toda essa discussão.

Kenneth Maxwell em seu clássico estudo sobre a Inconfidência Mineira, A Devassa da Devassa (Maxwell, 2010, p. 153), reforça a tese de que a Junta da Fazenda havia se transformado em um órgão administrativo colonial com certa autonomia de poder ao final do século XVIII. A Junta havia se tornado ao mesmo tempo em um centro de resistência e tensões políticas, mas isso se devia, sobretudo, à sua heterogênea formação. O órgão seria integrado por funcionários judiciais e civis, cargos ocupados por governadores e magistrados, e estes estavam "sob o controle do ministro dos Domínios Ultramarinos". O governador era ao mesmo tempo presidente da Junta e governo local, esta não era uma posição política que produzia a mesma uniformidade de interesses tais como presidir o Erário em Lisboa, até mesmo porque as Juntas ultramarinas estavam apenas em parte subordinadas ao mesmo Erário, pois grande parte de seus funcionários respondiam ainda ao Conselho Ultramarino. Sendo assim, esses órgãos ainda se submetiam, em tese, à jurisdição da tesouraria-mor do vice-reinado. Segundo Maxwell, "aí foi apresentada apenas uma parte da complicada e muitas vezes mal definida superposição jurisdicional imperante"(Maxwell, 2010, p. 117). No caso das Minas Gerais, a transformação dos órgãos regionais fiscais e administrativos em centros de poder, estaria ligada ao fato da Junta da Fazenda não ser "desafiada por qualquer autoridade de nível idêntico", diferentemente da Bahia ou Rio de Janeiro. Neste caso, não havia nenhum outro tribunal superior, inspetoria ou alfândega independente, segundo o autor, como havia nas outras capitanias (Maxwell, 2010, p. 153).

Esse era sem dúvida um aspecto relevante a ser destacado na compreensão da Junta e de seu corpo burocrático. Maxwell lembra que os interesses particulares dealguns magistrados como Alvarenga Peixoto (envolvido na Inconfidência Mineira) estavam indissociavelmente vinculados ao cargo que viriam ocupar na administração fazendária (Maxwell, 2010, p. 115). Como outros tantos magistrados funcionários da Real Fazenda, utilizavam de sua posição

3 lbid., p. 32.

tiempo\&economía

$\mathrm{N}^{\circ} 2$ - I semestre de 2015

p. 55 
privilegiada para promover seus próprios negócios, ignorando todas as restrições impostas aos seus cargos. Segundo Russell-Wood, havia uma "inevitável correlação entre o prestígio pessoal e a posição na sociedade, inerentes ao cargo desempenhado", características intrínsecas aos funcionários da administração fazendária (Russell-Wood, 1998, p. 183).

Chamamos atenção para essas questões porque elas envolvem uma parte importante negligenciada nas análises acerca das Juntas da Fazenda e que se concentram, sobretudo, na arrematação de contratos. Neste caso, estão focadas nos montantes contratados, nos vínculos e filiações políticos e mercantis de arrematadores e administradores dos contratos e, finalmente, na eficácia do sistema da administração fazendária das Juntas. São estudos esclarecedores e que muito tem contribuído para as recentes pesquisas acerca das arrematações e administrações de contratos régios (Guimarães, S.d.; Araujo, S.D; 2002b; Carrara, 2011; Antezana \&Vargas, 2006). Umbom exemplo é o trabalho desenvolvido por Angelo Carrara (Carrara, 2011). O sistema de contratos, responsável pela cobrança e arrecadação das entradas e dízimos, deveria possuir, segundo o autor, uma engrenagem perfeita para que ao final do período (triênio), o contratador pudesse honrar seu compromisso com a Real Fazenda. Isso não era exatamente simples. Os contratadores não contariam com os extravios, com administradores e demais funcionários inábeis ou corruptos, erros de cálculos, mudanças climáticas e demais situações imprevistas. Particularmente, Carrara analisa os volumosos contratos das entradas formalizados por João Rodrigues de Macedo nas capitanias de Minas Gerais, São Paulo, Goiás e Mato Grosso e dos dízimos de Minas. Conclui que as muitas incertezas não podem oferecer explicações plausíveis aos prejuízos resultantes do seu contrato para si próprio e para a Real Fazenda como havia acontecido com outros vários contratos no mesmo período. Entretanto, não exclui a possibilidade de haver uma relação perniciosa que marcava desde o início esses contratos. Citando outros estudos sobre o tema, admite, sobretudo nos casos em que envolviam os governadores, a possibilidade de contratos fraudulentos em que contratadores já endividados enviassem propostas irreais que jamais seriam pagas ao Erário (Carrara, 2011, p. 50). Nesse caso, importante dizer que dependiam fundamentalmente da aquiescência dos magistrados da Junta.

Outro bom exemplo de pesquisa sobre contratos e contratadores que procura compreender o funcionamento da Junta da Fazenda é o trabalho de Luiz Antonio Araujo (Araujo, 2002b). O autor nos apresenta dados sobre algumas das principais relações de contrato que se estabeleciam na Capitania de Minas Gerais e as formas de organização mercantil. Ao tratarmos das relações contratuais nessa capitania não podemos deixar de referir sua maior peculiaridade, a arrecadação dos quintos, que não se submetia a mesma lógica das arrematações, mas que incidia diretamente sobre elas. A "Lei Novíssima das Casas de Fundição", de 03 de dezembro de 1750, que extinguia a capitação e estipulava a derrama, pressionava fortemente os novos contratos. A partir desse período, e, sobretudo, com a reestruturação dos sistemas de contratos, com a criação da Junta da Real Fazenda, Araujo observa a maior preponderância e articulação entre grupos de negociantes coloniais. Para o autor, os grupos mercantis "coloniais" articulados sobreviveram inclusive à crise política que colocou em cena os envolvidos na Inconfidência Mineira e membros da Junta da Real Fazenda.

Alguns poucos estudos se dedicaram à criação das Juntas na América. Citaremos dois estudos que nos parecem representativos sobre essa perspectiva. Num primeiro texto (Cunha, 2011), de Alexandre Cunha, somos apresentados ao contexto de criação da Junta em Minas Gerais em interface com o Erário Régio. A partir da leitura de pareceres e alvarás, Cunha analisa 
o funcionamento das Juntas e, sobretudo, a defesa de sua manutenção por parte do Erário. As constantes queixas e até mesmo a Inconfidência não teriam abalado a credibilidade daquela repartição junto à administração metropolitana. A diminuição da arrecadação foi constantemente atribuída ao contrabando, mal maior, e não a problemas de gerenciamento. Para Cunha, apesar do aparente paradoxo, as Juntas correspondiam ao programa reformador pombalino e à sua lógica centralista, mesmo que elas representassem formas de poder mais autônomas no ultramar. Mesmo assim, elas respondiam bem ao novo enquadramento no qual ganhavam novas competências administrativas e passavam a se vincular a administração central, no caso, o Erário, e sem intermediários, como o Conselho Ultramarino (Cunha, 2011, p. 6).

Numa perspectiva um pouco distinta, apresentamos o trabalho do historiador português Miguel Dantas da Cruz (Cruz, 2011). As Juntas da Real Fazenda, segundo o autor, pertenciam à administração periférica do Estado português e faziam parte da política de centralização do império, sobretudo porque elas deviam responder à manutenção das forças militares e, em última instância, garantir recursos para a proteção dos territórios do rei. Essa perspectiva contrasta de imediato com aquele organismo fiscal, quase autônomo que servia aos interesses da elite mercantil ultramarina.

Cruz, no entanto, considera a criação do Erário Régio um marco disciplinador para as finanças públicas portuguesas e seu império. No caso do Brasil, lembra que as câmaras municipais tinham, até o século XVIII, preponderância sobre os tributos de custeamento das despesas militares e que não havia clareza, mesmo em Portugal, sobre a supremacia institucional entre os Conselhos da Fazenda e Ultramarino no gerenciamento da defesa dos territórios coloniais. As "insubordinações imprevistas" ou a Inconfidência Mineira seriam eventos pontuais, envolvendo contextos e personagens específicos que não deveriam comprometer a ação institucional. Com isso o autor reforçaria a ideia de que o processo de centralização, do qual as Juntas da Real Fazenda seriam o braço periférico, teriam sido muito bem sucedidos e jamais ameaçados por qualquer tipo de localismo.

Compreendemos a importância das pesquisas relacionadas acima para o estudo da administração fiscal na América, mas ponderamos que eles não ultrapassam a análise dessa instituição aos quadros da administração fiscal portuguesa, sobretudo correlacionando sua função à dinâmica econômica imperial que poderia gerar ou não uma maior autonomia política para os seus envolvidos. Isso corresponde também a sua correlação a movimentos anti-fiscais como contrapartida ao controle metropolitano. O estudo da fiscalidade no Brasil, como em outras colônias, esteve associado igualmente ao anti-colonialismo e com uma preocupação menor ou inexistente da história fiscal e financeira no Brasil que poderia também ser vinculada a um processo de unificação territorial.

\section{As complexas jurisdições: as administrações fiscais e eclesiásticas}

A criação do Erário Régio, como forma de manter um maior controle sobre as rendas do império português, ${ }^{4}$ influiu na reconfiguração do espaço administrativo americano.

4 Através do alvará de 22 de dezembro de 1761 em substituição à Casa dos Contos. http://iuslusitaniae.fcsh.unl. 
Essa mudança estava fundamentada em princípio pela lógica de centralização dos órgãos administrativos lusitanos em seu território e baseava-se em experiências administrativas similares na Europa. O Erário Régio foi estruturado a partir de quatro contadorias responsáveis pela arrecadação e administração das provedorias, almoxarifados e tesourarias responsáveis pelos contratos, rendas e direitos reais: a primeira destinava-se à Corte e à Estremadura; a segunda, correspondia às Províncias do Reino e das Ilhas dos Açores e Madeira; as duas seguintes compreendiam os demais territórios do Império, sendo que a América portuguesa não era compreendida como um território único. As relações da Bahia e do Rio de Janeiro, e respectivamente seus territórios adjacentes pertenciam a contarias distintas, ficando a primeira também responsável pela África ocidental e a segunda com a África oriental e Ásia. Observamos aqui que o território da América dividia-se certamente a partir da lógica dos interesses marítimos mercantis e não de uma possível unidade territorial. A mesma que compreenderia o Estado imperial do Brasil algumas décadas mais tarde. Podemos, entretanto, olhar pela lógica de que as reformas econômicas do período pombalino e do reinado de d. José I teriam representado, para o Império português, uma maior centralização e coesão administrativa e, particularmente, na América portuguesa ela teria se intensificado com o fim das capitanias hereditárias e com a criação da relação do Rio de Janeiro e a transferência do vice-reinado para aquela província.

A expansão territorial em direção às minas do ouro e a reconfiguração do espaço político, econômico e eclesiástico da América portuguesa nos setecentos impulsionava, por sua vez, a redefinição das suas jurisdições administrativas. Isso seria marcado pela criação de novas capitanias, como a de Minas Gerais, Goiás e Mato-Grosso, novas provedorias e novos bispados. Esses novos e importantes espaços conferiram a centralidade política ao Rio de Janeiro, sede do Vice-reinado a partir de 1763 (Hespanha, 2003. Magalhes, 2011; Silva, 1998). Também a criação do Tribunal da Relação em 1751, já representava uma clara projeção de unidade política e econômica no Centro-sul da América portuguesa. No plano eclesiástico, desde o início do século XVIII foram perceptíveis as mudanças. Quando foram publicadas as Constituições da Bahia, em 1707, existia apenas um arcebispado em Salvador (1551) e três recém-criados bispados (Rio de Janeiro, Pernambuco e Maranhão). A partir de então foram criados os bispados do Pará, São Paulo e Mariana, acrescidos das prelazias de Cuiabá (Mato-Grosso) e Goiás a partir do bispado do Rio de Janeiro. A expansão dos territórios na colônia e, sobretudo a expansão de fronteiras nas áreas mineradoras em um período de confrontos e de redefinição dos limites territoriais americanos, levava sem dúvida à necessidade de um maior controle do espaço e os novos bispados e prelazias tinham esse papel.

As jurisdições eclesiásticas não deveriam, no entanto, se sobrepor às jurisdições administrativas. ${ }^{5}$ A divisão jurídico-fiscal, apesar de uma separação territorial para as

pt/ ius/verlivro.php?id_parte=105\&id_obra=73\&pagina=1164. Acessado em 10/10/2014.

5 A relação jurídica e consequentemente a definição das jurisdições eclesiásticas e administrativas foram em grande parte definidas pelo padroado, o jus patronatus que, por bula papal concedia direito aos reis católicos como grão-mestres de gerir as expansões católicas incluindo a criação de bispados e suas nomeações. Essa relação não foi muitas vezes conturbada, negociada e de impasses para ambos os lados, mas no século XVIII, a política de centralização monárquica, mesmo que adotando uma vertente um iluminismo católico, compreendia a necessidade de submeter aquele mecanismo a um processo de secularização, ou de transformá-lo em um padroado "régio" de estado. O alvará publicado em 5 de março de 1779 por d. Maria seria o bom exemplo disso, pois submete a esse principio. Ver: Alvará sobre a defesa da jurisdição da Ordem de Cristo sobre as igrejas ultra- 
suas atribuições esbarrou rapidamente nas limitações jurisdicionais próprias da composição jurídico-administrativa portuguesa do Antigo Regime. Nos territórios coloniais pelo menos três questões se impunham com maior vigor: os imensos e ainda em grande parte desconhecidos espaços territoriais; os fortes litígios com as jurisdições eclesiásticas (que implicava a cobrança dos dízimos e o controle sobre novas freguesias); ${ }^{6}$ e a maior concentração de poderes em órgãos administrativos como era o caso das provedorias da Fazenda Real. Quando observamos a divisão inicial das contadorias, por exemplo, imaginamos a princípio que todas as arrecadações da Capitania de Minas estariam vinculadas à Relação do Rio de Janeiro, mas seu extenso território atingia as comarcas adjacentes da Relação da Bahia. Isso implicava que alguns Registros (postos fiscais) do extremo norte das Minas, como era o caso de Minas Novas, por exemplo, que ficara ao encargo da Relação da Bahia. Os valores do subsídio voluntário ${ }^{7}$ - imposto cobrado pela introdução de escravos, gado vacum, vinho e cachaça em toda a Capitania - passaram exclusivamente para o controle da contadoria da Bahia a partir de 1780. Essas alterações, sem dúvida, contribuíram para tornar o sistema de cobrança do Erário Régio bem mais complexo se comparadas ao seu princípio de racionalidade e centralidade administrativa. Embora as contadorias do Ultramar tenham sido extintas com a transferência da Corte, a divisão territorial jurídica permaneceu vinculada às Relações da Bahia e do Rio de Janeiro com a criação de novas contadorias.

Se o sistema fiscal do Erário Régio demonstrava demasiada complexidade por um lado, por outro lado, permitiu um melhor conhecimento sobre o conjunto a ser administrado ou pelo menos se produziu um maior acervo administrativo fazendário por parte dos magistrados que ocuparam importantes postos em distintas partes do Império e que buscaram interpretar, no contexto das reformas econômicas, o funcionamento do sistema e propor meIhorias a partir de suas particularidades. A mineração e sua crise, a circulação de moedas para a facilidade do comércio, a melhoria da produção e o conhecimento do território foram elementos comuns nas correspondências dos magistrados daquele órgão e também nos textos de alguns memorialistas do final do século XVIII.

marinas de 5 de março de 1779 - Biblioteca Nacional - Seção de Manuscritos. Localização: Il-30,34, 4.

6 Importante dizer que aqui não nos referimos aos litígios em torno da cobrança de dízimos, isto é, da arrecadação dos dízimos, uma vez que quando a Real Fazenda, ou mais especificamente as Juntas se tornam responsáveis pela arrecadação dos dízimos também se tornam responsáveis pelas despesas e rendimentos dos clérigos, a questão relatada aqui diz respeito à jurisdição territorial administrativa de correspondência entre bispados e capitanias de ponto de vista administrativo, isto é, o bispado de São Paulo ultrapassava sua capitania e adentrava a capitania de Minas Gerais, e isso acontecia com as demais. Essa não correspondência gerava às vezes tumulto entre paroquianos e certo interesse em mudança de localização administrativa, às vezes incentivada pelo próprio clero. Sobre a cobrança de dízimos mais especificamente, ver: CARRARA, e SANTIRO (2013).

7 Esse subsídio especial foi introduzido em 1756 com a finalidade de arrecadar fundos para a reconstrução de Lisboa após o terremoto e deveria findar após dez anos, o que não aconteceu. Esse subsídio, diferente de outros, cobrados na colônia, não teve caráter militar, ou mesmo de "utilidade pública e geral". Seu objetivo era específico e sua criação coincidiu com uma série de reformulações econômicas e fiscais. Foi cobrado pela provedoria e posteriormente pelas Juntas, quando o subsídio foi mantido na década de 1760 já havia o novo Erário Régio e as novas contadorias que na América dividia especialmente as relações da Bahia e do Rio de Janeiro. Na década de 1780, apesar de continuar sendo cobrado pela Junta da Real Fazenda, o controle das arrecadações passam exclusivamente para a contadoria da Relação da Bahia.

tiempo\&economía

$\mathrm{N}^{\circ} 2$ - I semestre de 2015

p. 59

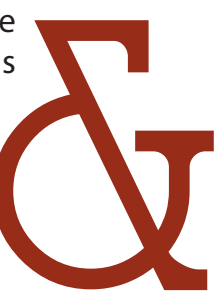


A "Instrução para o Governo da Capitania das Minas Gerais"8 do desembargador intendente José João Teixeira Coelho, seria um bom exemplo do que estamos falando. No início da década de 1780 ele apresentou o que seria, em suas próprias palavras, uma "compilação" das uteis informações para os governadores da capitania. No entanto, seus escritos ultrapassavam muito esse objetivo e continham o que ele também chamou de "reflexões judiciosas" ministradas pela experiência. Referia- se aos 11 anos frente à Intendência do Ouro em Vila Rica e do cargo de Procurador da Fazenda Real da Capitania.

Chamam atenção nesse texto a preocupação com o território, seu conhecimento e a proposta de adequações dos princípios normativos aos distintos espaços em sua constante mobilidade. Teixeira Coelho referia-se não apenas à sua experiência administrativa, mas também às suas viagens pelas "terras principais", a partir das quais reconhecia a ignorância administrativa, "até nas pessoas mais caracterizadas e que se empregam no Real Serviço" (Texeira Coelho, 2007, p. 168). No seu entender a necessidade daquelas "instruções" se fazia não apenas pela perda de uma memória administrativa consolidada, mas também pela inexistência de regras particulares àquela capitania "onde, muitas vezes, não [era] aplicável a legislação comum"(Texeira Coelho, 2007, p. 168).

Por essa razão a memória de Coelho e o seu contexto de produção tornaram-se aqui particularmente importante para nossa análise. Acentuava-se em sua "Instrução" a ideia de que o a administração e fiscalização do território minerador precisava ser aprimorada e que a mineração era apenas uma parte da economia da região. Assim sendo dissociava a ideia de rebeldia e insubordinação dos mineiros à de contrabandos ao Erário Régio (Boschi, 2007, p. 368) (Codet Silva, 2006). Afinado com o pensamento pragmático e racionalista dos administradores reformistas, Teixeira Coelho redigiu sua memória em sintonia com todos os modelos prescritos pela Real Academia de Ciências de Lisboa. O pragmatismo e tecnicismo aliado à experiência daquele que se propunha a instruir e apresentar propostas a problemas concretos de uma dada realidade.

Teixeira Coelho era português de Monsão e foi nomeado para o ultramar para o cargo de intendente. Segundo Caio Boschi, ser nomeado para a Intendência do Ouro em Vila Rica demonstrava grande distinção, pois era um cargo nuclear da administração imperial. ${ }^{9}$ Cargo que ele ocupou durante onze anos. A intendência do Ouro e Procuradoria da Real Fazenda nas Minas Gerais conferia prestígio e poder aos seus detentores, pois permitia controlar todo o volume de negócios e arrecadação da capitania. Em Minas, desde o ano de 1774 os intendentes de Vila Rica passariam a assumir acumulativamente o cargo de Procuradores da Real Fazenda, retirando-os da ouvidoria da comarca. Junto com os Governadores, os intendentes assumiam a recém instituída Junta da Real Fazenda nas Minas (1771) e eliminava os cargos de provedores e elevava aqueles órgãos ao fórum de tribunal. A Junta tinha poderes para deliberar sobre questões tributárias, organizava a arrematação dos contratos

8 A última versão de que temos notícia é o manuscrito de 1782 que foi recentemente publicado pela Coleção Tesouros do Arquivo sob a Organização de Caio C. Boschi em 2007. Cf. TEIXEIRA COELHO (2007).

9 Boschi. (2007, p. 93). O interessante é que Boschi diz que Coelho vem rapidamente para o Ultramar antes de passar por outras esferas da magistratura no Reino, o fato de ter sido indicado para Intendente nas Minas quer dizer que o cursus honorum foi quebrado e ele desvencilhou-se rapidamente das ligações com a Casa de Bragança. O que dizer então de Inácio Rebelo? 
e fiscalizava sua administração posterior, mantinha os balanços de todas as arrecadações para a coroa, deliberava, enfim, sobre os contenciosos jurídico-fiscais da capitania. Ocupar o cargo de intendente do Ouro e Procurador da Real Fazenda de Vila Rica conferia, portanto, não apenas grande poder, mas também prestígio entre a elite local. Boschi diz que havia um aparente paradoxo entre uma concepção fazendária racionalista no sentido de combater os descaminhos e, ao mesmo tempo abrir caminhos para uma elite local conduzir o processo político e econômico que se revelava principalmente nas arrematações de contratos (Boschi, 2007, p. 107). Dessa maneira, os homens de negócio portugueses entendidos por Kenneth Maxwell como "imigrantes", precisavam aprofundar e enraizar seus negócios de maneira inseparável do ambiente e dos bons da terra (Boschi, 2007, p. 107; Maxwell, 1977, p. 114).

\section{As fronteiras fiscais internas e a difícil unidade: as províncias de Minas Gerais e São Paulo}

Os contratos das alfândegas dos limites do sul da capitania de Minas enfrentavam sérios problemas jurisdicionais. O primeiro dizia respeito ao pertencimento dos territórios de novas freguesias ao bispado de São Paulo (locais pertencentes a Minas Gerais e, consequentemente, sujeitos a administração fiscal dessa província). O segundo refere-se ao temor de que novos descobertos e/ou novas vilas, criadas no final do século XVIII, pudessem ser introduzidos no processo da derrama (que assegurava o pagamento de 100 arrobas de ouro anualmente) simplesmente por pertencerem à capitania mineira. Teixeira Coelho já alertava para esses problemas e assim aconteceu com o "descoberto" do Jaguari, local onde se estabeleceu uma alfândega e que por sua vez substituiu a alfândega de Ouro Fino que já estava em litígio com os paulistas. Em 1771, os membros da câmera de São João de Atibaia (SP) se reuniram para solicitar ao Governador da Província de São Paulo providências contra o conde de Valadares (Governador de Minas) por invadir com seus destacamentos aqueles novos descobertos do Rio Pardo e do Jaguari porque apenas aos moradores das Minas "se tinham obrigado a pagar as cem arrobas anualmente como cláusula de que não chegando o quinto a completar as ditas cem arrobas", e ficando "as mais Capitanias do Cuiabá, Goiás, e São Paulo livres de pagarem a Sua Majestade o seu Real quinto de todo o ouro que extraíssem.... ${ }^{10}$ Para a cobrança dos quintos e das entradas nas Minas seria fundamental manter as fronteiras expandidas. Essa era sem dúvida a política empregada pela Junta da Fazenda Real, isto é, de fronteiras expandidas e de incentivos ao crescimento do número de vilas e freguesias vinculadas àquela arrecadação. Das 16 vilas constituídas no período colonial na capitania mineira, 7 foram criadas entre a última década do século XVIII e o início do século XIX e 6 estavam localizadas nesta região. Eram elas: Vila de São Bento do Tamanduá (Itapecerica), Vila da Campanha da Princesa (Campanha), Vila de Barbacena (Barbacena), Real Vila de Queluz (Conselheiro Lafaiete), Vila de Santa Maria do Baependi (Baependi), Vila de São Carlos do Jacuí (Jacuí) (Carneiro \& Matos, 2010). Essa política esteve associada também à fixação dos postos fiscais (alfândegas).

10 - II- 1038 - 1118. Seção de Manuscritos da Biblioteca Nacional Rio de Janeiro. 
Inácio Rebelo, Intendente do Ouro de Vila Rica e membro da Junta da Fazenda Real (a. 1790 a 1815) ficou responsável por fiscalizar os contratos das entradas, quintos e dízimos nas Minas e deu especial atenção aos limites ainda pouco precisos entre Minas e São Paulo. Isso foi possível observar nas correspondências em que o Intendente manteve com algumas autoridades portuguesas, entre elas: com d. Rodrigo de Souza Coutinho, quando este esteve à frente do Erário Régio, e principal articulador de projetos políticos e econômicos que promovessem uma maior unidade territorial na América portuguesa. Em 1807 o Conselho Ultramarino havia indicado Rebelo para uma diligência a fim de definir as hierarquias de jurisdições entre as vilas de São João Del Rei (MG) e Campanha da Princesa (MG) em relação aos arraiais de Baependí, Pouso Alto, Aiuruoca, Baixa do Funil, Jacuí, e Cabo Verde (ver mapa abaixo). Segundo a normatização anterior, essas localidades deveriam estar vinculadas à vila de São João Del Rei, no entanto o parecer de Rebelo não apenas priorizava a vila de Campanha com o argumento do avanço das fronteiras e de seu comércio como, estabelecia uma "centralidade" baseada nas distâncias territoriais e não no antigo princípio de primazia das "cabeças" de comarca. No ano seguinte, seu sobrinho seria indicado para o cargo de Juiz de Fora de Campanha da Princesa e nos anos subsequentes os termos de Jacuí e Baependi (regiões que estavam em disputa com São Paulo) foram elevadas à categoria de vilas. Em 1814, Rebelo dava novo parecer sobre as freguesias das novas vilas. Dizia não ser necessário elevar Franca (SP) à qualidade de Vila, mas sim subordiná-la à Jacuí (MG). Não pretendia que aquela freguesia fizesse parte da província paulista e alegava para isso que todos os seus moradores atestavam pertencer à Comarca do Rio das Mortes e serem mineiros. ${ }^{11}$ Nessa mesma época, foram realizados mapas descritivos das atividades dos mineiros nas vilas de Campanha, Baependi e Jacuí. Apuração das listas dos devedores da Fazenda Real e diversas devassas sobre circulação bilhetes e moedas falsas. O mais longo processo no período envolveu 48 testemunhas, e a prisão de três grandes negociantes que possuíam vínculos com casas de comércio no Rio de Janeiro e Minas Gerais e residiam em pontos estratégicos do caminho novo (ligando as duas regiões).

Como Intendente do Ouro em Vila Rica e responsável pela arrecadação do subsídio voluntário, Rebelo tinha forte atuação nos postos fiscais. Suas correspondências demonstram o vasto alcance de sua atuação, entretanto, interessa-nos aqui uma região que particularmente se transformava no final do século XVIII, o sul de Minas. Nessa região ele passou a atuar mais frequentemente devido ao conflito de jurisdição e que afetava uma comarca em franca expansão, a Comarca do Rio das Mortes. Neste sentido, corroboramos a tese já apresentada por Kenneth Maxwell sobre o propósito de alguns magistrados em concentrar seus interesses econômicos na região da Comarca do Rio das Mortes.

Vejamos, inicialmente, algumas das características daquele espaço em formação. Os contratos das alfândegas dos limites do sul enfrentavam problemas com as inúmeras modificações e questionamentos de jurisdição tanto no que dizia respeito ao pertencimento dos territórios de novas freguesias ao bispado de São Paulo, quanto ao temor dos novos descobertos serem introduzidos no processo da derrama. O que não aconteceria, caso ficassem fora da jurisdição de Minas Gerais.

11 II-36,06,028 Fundo Minas Gerais Seçao de Manuscritos. Biblioteca Nacional do Rio de Janeiro. 
No caminho "velho" ou caminho das Minas passando por São Paulo para se chegar aos portos, foram instalados os seguintes postos fiscais: Capivari, Itajubá, Jacuí, Jaguarí, Mandu, Ouro Fino, Picu, Rio Grande, Sapucaí e Sapucaí Mirim. O Registro do Capivari ficava situado no antigo caminho que ligava Guaratinguetá (São Paulo) à vila de São João Del Rei. O postos de Mandu funcionou até a década de 1770 e foi transferido para o Jaguari e funcionavam respectivamente nos atuais municípios Pouso Alegre e Camanducaia. A alfândega do Ouro Fino começou a funcionar na década de 1760 na região onde hoje seria o município homônimo do sul de Minas. A elevação da Capela de São Francisco de Paula de Ouro Fino à condição de freguesia pelo bispado de São Paulo, ainda em 1749, deu início a uma longa disputa. Com a intervenção régia, a freguesia passou ao bispado de Mariana (MG) em 1765. Isso, por sua vez, não resolveu definitivamente os problemas de limites na região, que somente começou a se estabilizar com a criação da Vila de Campanha da Princesa em 1799. A disputa em torno da freguesia de Ouro Fino desdobrou ainda numa retomada de sua posse pela Diocese de São Paulo em 1775, o que levou à mudança no posicionamento da alfândega em 1777 para a “Ponte Nova” do Rio Jaguarí próximo hoje do atual município de Bragança Paulista (SP). No ano seguinte uma nova mudança restituiu o posto fiscal dentro dos limites da província mineira.

Este foi um caso intrincado e que envolveu o famoso contratador João Rodrigues de Macedo. Em 1777, como dissemos, o registro que estava na freguesia do Ouro Fino, disputada pela diocese de São Paulo, foi enviado para a "Ponte Nova" do Jaguarí (atualmente Estado de São Paulo) por Ordem Régia. ${ }^{12}$ Pelo mesmo documento justificava-se a mudança por ser mais rentável e benéfica à comarca que pertencia, Rio das Mortes, e mandava a Junta da Fazenda de Minas Gerais tomar as devidas providencias em relação às obras necessárias. Isso significava naquele momento de disputa de jurisdição tanto com a diocese de São Paulo, como com a câmara de São João de Atibaia.

As disputas entre as jurisdições da diocese de São Paulo, governos das capitanias e consequentemente das Juntas de suas respectivas fazendas repetia-se em outras freguesias. Em 1767, o Padre Pedro Francisco Machado defendia-se das acusações de ter entregado a lgreja do Jacuí aos mineiros sem, contudo, ter autoridade para isso, isto é, sem ser seu pároco responsável. Essa era uma acusação da diocese de São Paulo, afinal de contas aquela freguesia Ihe pertencia. O Padre Machado, por sua vez, escrevia ao Governador de Minas dizendo que havia chegado a Jacuí no ano de 1763, e que naquele tempo tudo pertencia "às Minas"; "foi preciso tomar sobre os meus fracos ombros, o peso desta Igreja; a tempo que o Senhor General das Minas veio ratificar as posses; que dizia muito antes estavam feitas por parte daquela Capitania; e que o Eclesiástico devia igualar as mesmas balizas".13 Com certeza o povoado do Jacuí já pertencia à comarca do Rio das Mortes, no entanto, a freguesia pertencia à diocese de São Paulo. Para resolver a situação o prelado referia-se ao princípio do padroado e à primazia do governo secular sobre aquela jurisdição eclesiástica. ${ }^{14} \mathrm{O}$ objetivo era de se

12 MS 580 (20) Documento 08. Seção de Manuscritos. Biblioteca Nacional, Rio de Janeiro.

13 MS 553 (19) Documento 03. Seção de Manuscritos. Biblioteca Nacional. Rio de Janeiro.

14 Ver: http://iuslusitaniae.fcsh.unl.pt/verlivro.php?id_parte=109\&id_obra=73\&pagina=340. Acessado en em 30/10/14. Em um doc. anônimo sobre a administração eclesiástica nas Minas Gerais em fins do século XVIII, encontramos um interessante relato sobre o tema. $\mathrm{O}$ autor, que em determinado momento se define como bispo, diz que o referido Alvará que estabeleceu que os párocos regulares não pudessem servir as suas Igrejas sem instituição e aprovação dos Bispos (...) e que os mesmos Bispos não pudessem jubilar, e dar licença aos 
conseguir paulatinamente centralizar sob a jurisdição do Estado o controle do território e do monopólio da fiscalização e da lei.

Para tentar minimizar ao máximo tais disputas, a Junta da Fazenda de Minas defendia em $1809^{15}$ a extinção das alfândegas centrais e manutenção apenas dos postos verdadeiramente limítrofes da capitania. Entre eles, destacava-se o de Jacuí, solicitando a transferência de sua sede do arraial para a margem esquerda do rio Pardo (considerado um limite natural) ou para o córrego do Ouvidor, pelo fato de se poder conseguir estabelecer o posto fiscal no limite exato da divisão política e administrativa com São Paulo.

Outro relatório de Inacio Rebelo, também de 1814,16 emitia parecer sobre anecessidade de continuar a expansão do território em detrimento das fronteiras já estabelecidas com São Paulo. Lembrava que todo o território do sul de Minas havia passado por mudanças pelas quais ele havia se empenhado, as primeiras freguesias de Baependi, Pouso Alto, Aiuruoca, Baixa do Funil, Jacui, Cabo Verde vinculando-se à Vila da Campanha da Princesa, conforme determinação do Conselho Ultramarino. Prosseguia informando que a criação das vilas de Jacui e Baependi produzia novas demandas. A vila de Jacuí, que antes havia sido um julgado, era também uma reivindicação dos seus moradores sob o argumento de sua extensão e rendimentos. Isso por sua vez criava a necessidade de definir o seu termo, dotando assim a condição de freguesia à Franca, subordinada a essa nova Vila. Assim definia a questão:

Sempre que alguns novos colonos penetram e cultivam os matos virgens infestados de gentios, ficam sendo fregueses da mesma freguesia por onde entravam, assim muitos se foram estendendo os termos das vilas que pertenciam aquelas freguesias e, por consequência as capitanias. E por essa mesma razão deve a nova freguesia de Franca ser do termo de Jacui e desta Capitania. Veja-se no mapa de população incluso, onde quase todos a quem se declara a naturalidade são das freguesias desta Capitania e da Comarca do Rio das Mortes que certamente por entrarem aqueles matos não os foram penetrando pela Capitania de São Paulo.

É interessante observamos aqui a lógica centrífuga. As Minas se expandiame haveria uma lógica natural em manter os colonos dentro da mesma jurisdição político-administrativa de onde partiam. Além disso, ele alegava que havia uns mapas e documentos autênticos que demonstravam que Franca ficava aquém do Rio Pardo e que os Oficiais do Regimento de linha atestavam que essa era a divisão das capitanias e por isso sempre utilizaram esse princípio para patrulhar o território. Enfim, não havia mesmo precisão e todo aquele território estava aberto às disputas políticas e interesses econômicos.

Os conflitos jurisdicionais nos revelam claramente um território que, em menos de uma década de sua independência e constituição do Império do Brasil, encontrava-se fragmentado

cônegos, fazendo-se a este respeito as mais declarações, que constam do segundo, igualmente dimanaram da Jurisdição Eclesiástica, e Ordinária, que está no Grão Mestrado da Ordem de Cristo, achando-se neles clausulas nada ambíguas, e claríssimas, que assim o comprovam. Papéis do Brasil. Códice 15, mic. 4580. Arquivo Nacional, Lisboa.

15 MS 580 (108) Documento 74. Seção de Manuscritos. Biblioteca Nacional, Rio de Janeiro.

16 II-36,06,028. Fundo Minas Gerais. Seçao de Manuscritos. Biblioteca Nacional, Rio de Janeiro. 
e separado por barreiras fiscais. O grande desafio que se apresenta é a compreensão da transição das instituições fiscais, como o caso das Juntas da Fazenda, que apenas foram extintas em 1831 (nove anos após a Independência), para a perspectiva de um Estado unificado e autônomo. Sem dúvida não há como não analisar as trajetórias e interesses políticos e econômicos de seus membros, sobretudo magistrados que se fixaram com suas famílias e seus negócios. Alguns seguiram uma longeva carreira política, como foi o caso de Manoel Inácio de Melo e Souza, sobrinho do Intendente Inácio Rebelo. Ele teria a tarefa frente à Junta Provisória de Governo de conciliar os diferentes projetos locais a interesses de âmbito territorial mais amplo. A transferência da Corte, em 1808, já havia criado algumas diretrizes nesse sentido, sobretudo no fato de subordinar as diversas repartições fazendárias ao novo "centro", o Rio de Janeiro. Entretanto, as diferenças ainda persistiam após a Independência e em muitos sentidos prefiguravam as discussões em torno do das propostas federalistas. Esta é, com certeza, uma questão que merece ser aprofundada em futuros estudos.

\section{Anexos}

Mapa de toda a Extensão da Campanha da Princesa

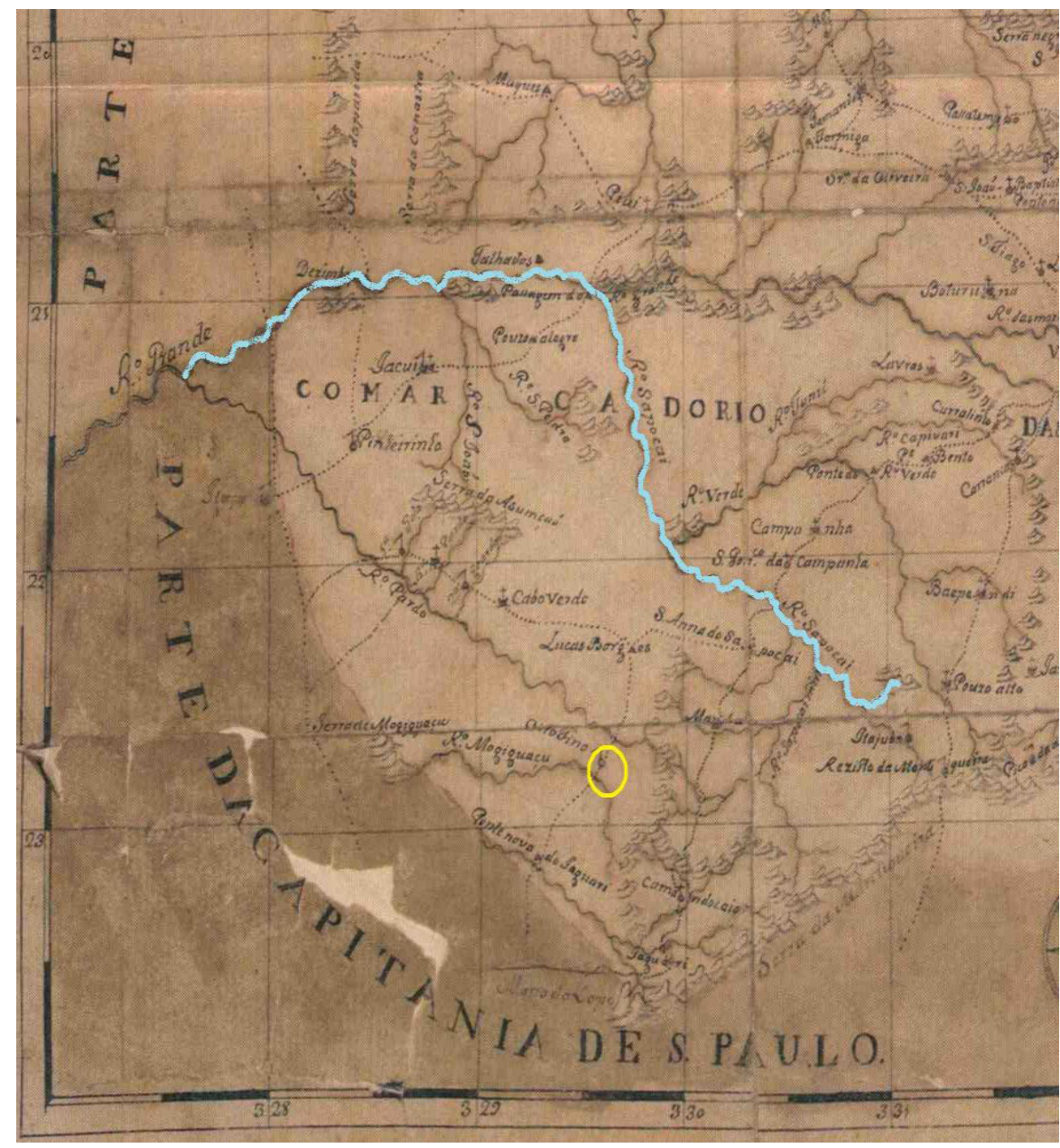

Figura 1. Francisco Sales - (1799) 1800.

Fonte: Costa et al. Cartografia das Minas Gerais: da capitania à província. BH. Editora UFMG. 


\section{Demarcação da Divisa do Rio Sapucaí e o Registro de Ouro Fino}

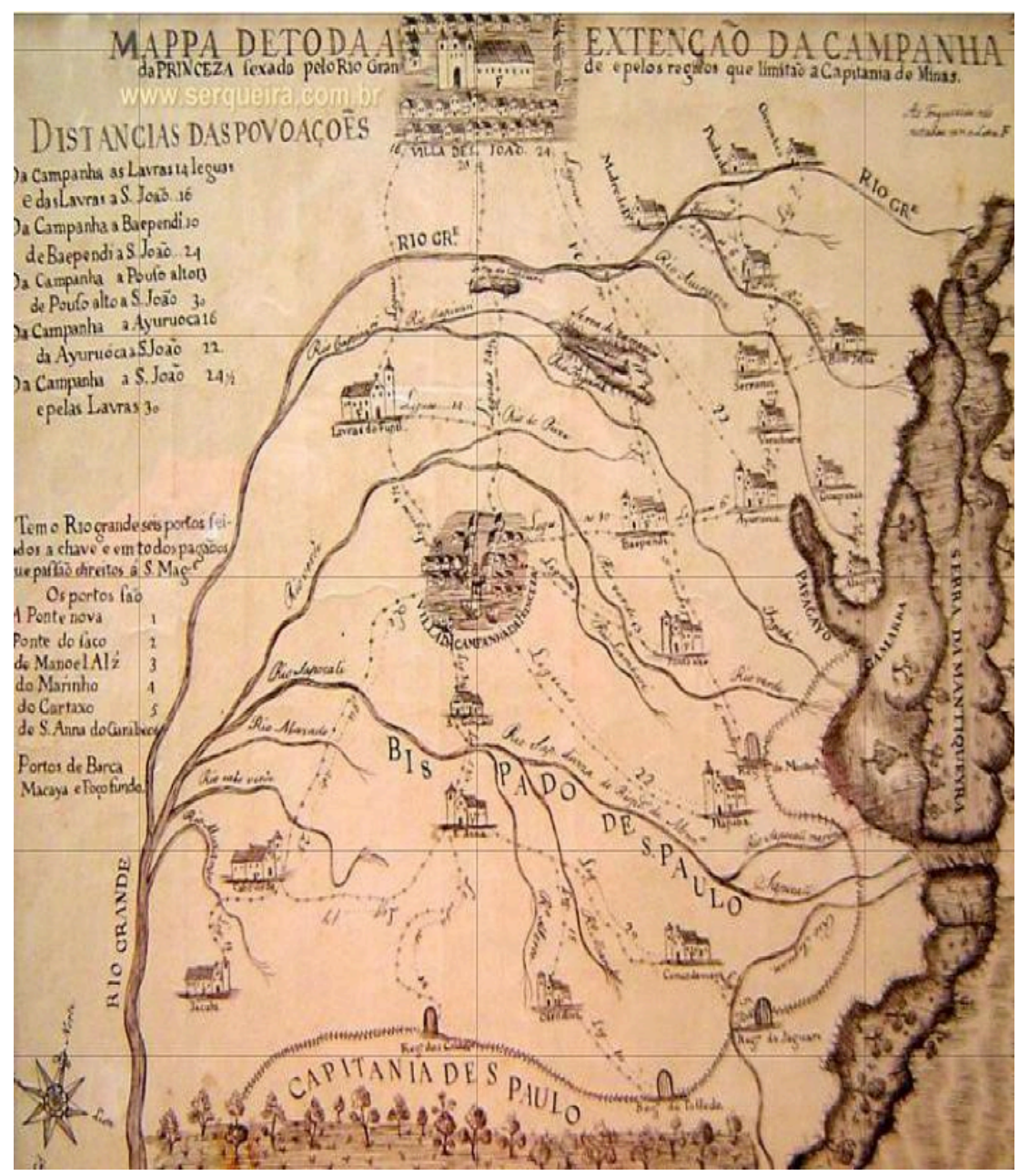

Fonte: Mapa de Jose Joaquim da ROCHA. Comarca do Rio das Mortes (1778)(limite com a Capitania de São Paulo), APM. Acesso em10/10/2014.

http://www.siaapm.cultura.mg.gov.br/modules/grandes_formatos/brtacervo.php?cid=920\&op=1

\section{Referencias}

Antezana, S. e Vargas, L. (2006). Os contratadores dos caminhos do ouro das Minas setecentistas: estratégias mercantis, relações de poder, compadrio e sociabilidade (1718-1750). Dissertação de Mestrado. UFMG.

Araujo, L. A. (2002a). Contratos e Tributos nas Minas Setecentistas - O estudo de um caso João de Souza Lisboa (1745-1765). Dissertação de Mestrado, UFF, Niterói. 
Araujo, L. A. (2002b). Contratos nas Minas setecentistas: estudo de um caso - João de Souza Lisboa (1745-1765). http://www.cedeplar.ufmg.br/diamantina2002/textos/D02.PDF. Acessado 04/05/14.

Araujo, M. e Viveiros, L. (s. d.). Contratos régios e contratadores da capitania de São Paulo, 1765-1808. http://www.fea.usp.br/feaecon/media/fck/File/Maria_acessado 28.09.14.

Boschi, C. (2007). Estudo crítico. Em: Instrução para o Governo da Capitania de Minas Gerais. José João Teixeira Coelho. Belo Horizonte: Fundação João Pinheiro.

Carneiro, P. A. S. e Matos, R. S. (2010). Geografia histórica da ocupação da Zona da Mata Mineira: acerca do mito das áreas proibidas. Anais do XIV Encontro Cedeplar. Diamantina, http:// www.cedeplar.ufmg.br/seminarios/seminario_diamantina/2010/D10A081.pdf. Acessado em 20/04/14.

Carrara, A. (2011). Administração dos Contratos da Capitania de Minas: O Contratador João Rodrigues de Macedo, 1775-1807. América Latina en la Historia Económica, 35: 29-52.

Carrara, A. e Santiro, E. (2013). Historiografia econômica do dízimo agrário na Ibero-América: os casos do Brasil e Nova Espanha, século XVIII. Estud. Econ. [online], 43 (1) [citado 2015-04-22], pp. 167-202. Disponível em: <http://www.scielo.br/scielo.php?script=sci_arttext\&pid=S0101-41612013000100007\&lng=en\&nrm=iso >. ISSN 0101-4161. http://dx.doi. org/10.1590/S0101-41612013000100007. Acessado em 01/07/2015.

Cloclet Silva, A. R. (2006). Minas no contexto da "acomodação": as relações de poder, as práticas políticas e as tessituras das identidades. Revista Aulas: Dossiê Identidades Nacionais, (2).

Cunha, A. M. (2010). A Junta da Fazenda em Minas Gerais e seu diálogo com o Erário Régio na Metrópole em fins do século XVIII: reflexão sobre os limites às reformas Econômicas na colônia dentro da administração fazendária portuguesa. ANPEC. http://www. anpec.org.br/encontro2010/inscricao/arquivos/0006c2884023a1bd870747fcd624238e3ba.pdf. Acessado em 03/05/14.

Cruz, M. D. (2011). Estado e centralização na monarquia portuguesa. A administração e a defesa do Brasil entre o Erário Régio e as Juntas da Fazenda (1761-1801). Associação Portuguesa de História Econômica e Social, .http://www4.fe.uc.pt/aphes31/papers/sessao_3f/ miguel_dantas_cruz_paper.pdf. Acessado em 05/05/14.

Guimarães, C. G. (s. d.). Contratos e Contratadores do Rio de Janeiro, 1760-1790. Mimeo.

Hespanha, A. M. (2003). As estruturas políticas em Portugal na época moderna. UNL, www.unl. pt (acessado em 11/04/2014).

Magalhaes, J. R. de (2011). Labirintos Brasileiros. São Paulo: Alameda.

Maxwell, K. (1977). A devassa da Devassa: A Inconfidência Mineira: Brasil Portugal (1750-1808). Rio de Janeiro: Paz e Terra.

Russell-Wood, J. R. A. (1998). A dinâmica Social: Governantes e agentes. In: Francisco Bethencourth e Kirti Chauduri (Org.). História da Expansão Portuguesa. V. 3. Lisboa: Circulo de Leitores.

Silva, A. C. N. da. (1998). O Modelo Espacial do Estado Moderno. Lisboa: Estampa. 
Teixeira Coelho, J. J. (2007). Instrução para o Governo da Capitania de Minas Gerais. Organização, transcrição e textos introdutórios de C. C. Boschi. Belo Horizonte: Arquivo Público Mineiro, Instituto Histórico e Geográfico. 